\title{
Etiological Factors and Management of Low Vision in a Tertiary Health Institution in Niger-Delta, Nigeria - A 5-Year Review
}

\author{
Onua $\mathrm{AA}^{\mathbf{1}}$ and Pepple $\mathrm{GF}^{2 *}$ \\ ${ }^{1}$ Department of Ophthalmology, University of Port Harcourt, Nigeria \\ ${ }^{2}$ Department of Surgery, Rivers State University, Nigeria \\ *Corresponding Author: Pepple GF, Department of Surgery, Rivers State University, \\ Nigeria.
}

Received: October 26, 2021

Published: November 09, 2021

(C) All rights are reserved by Onua AA and

Pepple GF.

\begin{abstract}
Objective: To evaluate the causes and management of low vision presenting at the department of Ophthalmology, University of Port Harcourt Teaching Hospital (UPTH), Niger-Delta, Nigeria from 20014 to 2018.

Methodology: A retrospective review of clinical records from the low vision clinic of UPTH from 2014 till 2018. Data extraction: Data on low vision pathologies including the demographics of patients seen from 2014 to 2018 were obtained from the low vision clinic register and entered into Microsoft Excel sheet. Data analysis: Data from Microsoft Excel sheet were exported to Statistical Package for Social Sciences version (SPSS) version 25 for statistical analysis. Relevant data were presented in tables and charts. Statistical significance was performed using Chi square and statistical significance was set at $\mathrm{p} \leq 0.05$.

Results: A total of 108 patients with various low vision problems were seen during a 5-year period at the Low Vision Clinic of the University of Port Harcourt Teaching Hospital spanning from 2014 to 2018 . The commonest causes of low vision were Glaucoma (35.2\%), Oculocutaneous Albinism (18\%) and Degenerative Myopia (8\%). The Mean age of the patients was 41.4 \pm 22.5 ; with a range of 2 to 81 years. Male to Female ratio was 1:1.8.

Conclusion: Glaucoma, Oculocutaneous Albinism and Degenerative Myopia were the predominant causes of low vision. Telescopes and spectacle magnifiers were the most commonly prescribed devices used to ameliorate their vision impairment.
\end{abstract}

Keywords: Etiology; Low Vision; Niger-Delta

\section{Introduction}

Low vision constitutes significant functional, economic and social challenge to the individual patients as well as economic burden to the society. According to the World Health Organization (WHO), low vision is "an impairment of visual function with a visual acuity of less than 6/18 to light perception (PL) in the better eye or a visual field of less than 10 degrees from the point of fixation, with the ability to use the vision for planning and/or execution of tasks for which vision is essential even after treatment and/or standard refractive correction" [1]. However, individuals who fall outside this definition (outside the boundaries of VA<6/18 to LP) may also benefit from low vision services, such as those with a corrected VA of at least 6/18 in one or both eyes but who have, for example, paracentral scotomas, reduced contrast sensitivity, or pronounced photophobia [1,2]. Therefore, the term "functional low vision" (FLV) is more encompassing than the WHO definition of low vision which is solely based on presenting visual acuity.

In the year 2014, about 285 million people were estimated by the World Health Organization (WHO) to be visually impaired worldwide of which 246 million had low vision [3]. More than $90 \%$ 
of the world's visually impaired live in low-income settings and there are huge economic and social consequences associated with visual mobility and considerable mortality $[4,5]$.

In Nigeria, according to the Nigerian National Survey of Blindness and Low Vision in 2005-2007, the prevalence of low vision was 3.5\%; 95\% CI, 3.1-3.9\%) [6]. Low vision remains an important public health problem which requires the needed attention by all stake holders [7], and it is heart-gladdening to know that, $75 \%$ of visual impairment is avoidable (preventable and curable) [2]. The global target of the WHO Prevention of Blindness Program "VISION 2020: The Right to Sight Initiative "is to reduce blindness prevalence to less than $0.5 \%$ in all countries, or less than $1.0 \%$ in any community [8].

The causes of low vision vary across the world. In the more developed countries of the United Kingdom and the United States of America, studies suggest that the leading cause of low vision and blindness among white population is age-related macular degeneration [9-11]. According to a study by Vijaya., et al. in Chennai, an urban South Indian population, the prominent causes of low vision in subjects aged 40 and above were uncorrected refractive errors and cataract [12].

In Southern Sudan, Ngondi., et al. found that trachoma and cataract were the leading causes of low vision [13]. Nigeria, glaucoma, corneal opacity and age-related macular degeneration were the identified commonest causes of low vision [6].

However, Monye., et al. reported that oculocutaneous albinism, glaucoma, retinitis pigmentosa, and high refractive errors were responsible for low vision in Southeast Nigeria [14]. In Ekiti state, South West Nigeria, cataract was found to be the leading cause of visual impairment accounting for $29.9 \%$, followed by primary glaucomas $(17.8 \%)$, retinal disorders (13.8\%), refractive error (11.2\%), corneal disorders (10.8\%) and macular diseases (7.4\%) [15].

Most of the known causes of low vision are preventable and alleviated by medical, surgical treatment as well as the use of optical devices (low vision aids). In 1999, the World Health Organization (WHO) in collaboration with the International Agency for the Prevention of Blindness (IAPB) initiated "VISION 2020: the Right to Sight" with the aim of eliminating avoidable blindness $[16,17]$. Cataract surgeries, spectacles for near and distant vision, provision of low vision aids such as hand-held magnifiers, standing magnifiers telescopes, closed circuit television (CCTV), electronic magnifiers and electronic telescopes, counselling and referral to the School for the Blind are some of the measures offered to low vision patients to improve their vision and work performance.

\section{Materials and Methods}

A retrospective review of clinical records from the low vision clinic of UPTH from 2014 till 2018. All consecutive cases of low vision patients of all ages presenting at the Low Vision Clinic of the University of Port Harcourt Teaching Hospital within the study period were included in the study. This study was approved by the Institutional Ethics Review Board and was performed in accordance with the tenets of the Helsinki Declaration for research involving human subjects. Data extraction: Data on low vision pathologies and the demographics of patients seen were obtained from the low vision clinic register and entered into Microsoft Excel sheet. Data analysis: Data from Microsoft Excel sheet were exported to IBM Statistical Package for Social Sciences version (SPSS) version 25 for statistical analysis. Relevant data were presented in tables and charts. Statistical significance was performed using Chi square and statistical significance was set at $\mathrm{p} \leq 0.05$.

\section{Results}

A total of 108 medical records of patients with low vision were studied. The ages of the patients ranged from 2 to 81 years, with a mean age $41.4 \pm 22.5$ years. The Female: Male ratio was 1:1.8. A high proportion of the study population, 20 (18\%), were within the younger age group of 21 to 30 years. The difference in the ages of male and female participants in this study was not statistically significant $(p=0.9)$ [Table 1].

\begin{tabular}{|l|c|c|c|}
\hline $\begin{array}{l}\text { Age Group } \\
\text { Years) }\end{array}$ & Males (\%) & Females (\%) & Total (\%) \\
\hline $0-10$ & $4(4)$ & $3(3)$ & $7(7)$ \\
\hline $11-20$ & $11(10)$ & $5(5)$ & $16(15)$ \\
\hline $21-30$ & $11(10)$ & $9(8)$ & $20(18)$ \\
\hline $31-40$ & $8(7)$ & $6(6)$ & $14(13)$ \\
\hline $41-50$ & $8(7)$ & $4(4)$ & $12(11)$ \\
\hline $51-60$ & $8(7)$ & $3(3)$ & $11(10)$ \\
\hline $61-70$ & $10(9)$ & $3(3)$ & $13(12)$ \\
\hline $71 \&$ Above & $9(8)$ & $6(6)$ & $15(14)$ \\
\hline Total & $69(62)$ & $39(38)$ & $108(100)$ \\
\hline Pearson Chi Square Value =2.731; df = 7; p-value $=0.9$ \\
\hline
\end{tabular}

Table 1: Age and Gender Distribution of the Study Population. 
Telescope was the most frequently preferred low vision aid among the study population (38\%). Other devices were spectacle magnifiers (15.7\%), hand-held magnifiers (8\%), standing magnifiers (7\%), electronic magnifiers (1\%), photochromic anti-reflective lenses (1\%) and Contact lens (1\%). Thirty-two percent of the study population were referred for various rehabilitative treatments and procedures [Figure 2].

\begin{tabular}{|l|c|c|c|}
\hline Low Vision Device & $\begin{array}{c}\text { Male } \\
\mathbf{( \% )}\end{array}$ & $\begin{array}{c}\text { Female } \\
\mathbf{( \% )}\end{array}$ & Total (\%) \\
\hline Telescope & $25(23.2)$ & $\begin{array}{c}16 \\
(14.8)\end{array}$ & $41(38.0)$ \\
\hline Spectacle Magnifier & $12(11.1)$ & $5(4.6)$ & $17(15.7)$ \\
\hline Hand-held Magnifier & $6(5.5)$ & $2(1.8)$ & $8(7.5)$ \\
\hline Standing Magnifier & $3(2.9)$ & $4(3.6)$ & $7(6.5)$ \\
\hline Contact Lens & $1(0.9)$ & $0(0)$ & $1(0.9)$ \\
\hline Electronic Magnifier & $0(0)$ & $1(0.9)$ & $1(0.9)$ \\
\hline $\begin{array}{l}\text { Photochromic } \\
\text { Anti-reflective Lens }\end{array}$ & $1(0.9)$ & $0(0)$ & $1(0.9)$ \\
\hline Referral (Rehabilitation) & $21(19.4)$ & 11 & $32(29.6)$ \\
\hline Total & $69(63.9)$ & $\begin{array}{c}39 \\
((36.1)\end{array}$ & $108(100)$ \\
\hline Pearson Chi Square Value $=2.291$ Fisher's p-value=0.718 \\
\hline
\end{tabular}

Table 2: Gender Distribution of Preference of Low Vision Devices in the Study Population.

More participants of this study (23.2\% males and $14.8 \%$ females) preferred telescopes to other devices. A total of 32 (29.6\%) participants were referred for various rehabilitative measures.

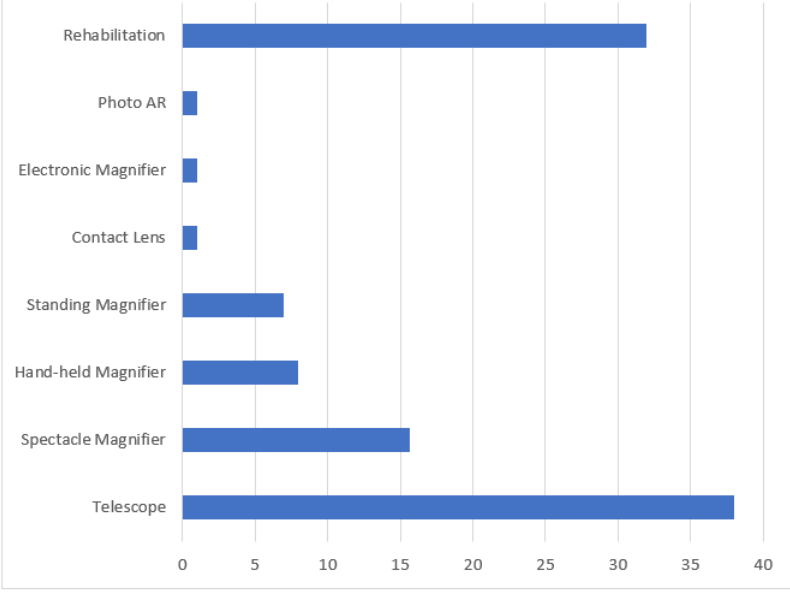

Figure 2: Low vision devices used among the study population (in Percentage).

\section{Discussion}

The University of Port Harcourt Teaching Hospital is one of the 8 five-star Teaching Hospitals in Nigeria. It is located at its permanent site at Alakahia, beside University of Port Harcourt and is a busy tertiary health facility affiliated to the College of Health Sciences University of Port Harcourt. The hospital has 803 beds; 20 of which are for the Department of Ophthalmology. The low vision clinic in the Ophthalmology department was established in 2014. It runs every Wednesdays by an optometrist trained in low vision.

The low vision clinic serves as a catchment center for patients in Rivers State and its environs as well as referral center for other 
hospitals in the neighboring states of Bayelsa, Abia, Imo and Delta states in Nigeria.

This study is a 5-year review of the etiological factors and management of low vision in the low vision clinic in the UPTH from 2014 to 2018. In this retrospective study, a total of 108 cases were reviewed. The ages of the patients ranged from 2 to 81 years, with a mean age $41.4 \pm 22.5$ years. The female: male ratio was $1: 1.8$. A high proportion of the study population, 20 (18\%), were within the younger age group of 21 to 30 years. The difference in the ages of male and female participants in this study was not statistically significant $(\mathrm{p}=0.9)$ [Table 1].

This study closely compares with the study of Ackuaku-Dogbe., et al. in Korle $\mathrm{Bu}$ Teaching Hospital, Accra, Ghana in which there was a total of 604 cases with average age of 40.55 years (SD \pm 6.95 ) [18]. In the Ghanian study, there was no statistically significant difference between the mean age in both sexes (p-value =1.000) [18]. Similarly, in a hospital-based study in Ekiti State Nigeria by Ajayi., et al. 445 cases of visual impairment with age range from 2 years to 105 years and a mean age of 53.6 years \pm 23.6 years with female preponderance (1:1.1) [15]. However, in a population-based study of individuals 40 years and above, the Nigerian National Survey of Blindness and Visual Impairment (2005 to 2017) found out that the mean age of persons with low vision was 55.9 years (SD \pm 12.4 ) with the greatest number being aged 40 to 49 years [7]. Although 13,591 individuals of 40 years and above were examined in the $\mathrm{Ni}$ gerian National Survey, the mean age of males with FLV was very similar to that of females (67.3 years vs. 67.0 years, respectively) [6]. The Nigerian National Blindness and Low Vision Survey was skewed to adult population of $\geq 40$ years of age.

The leading causes of visual impairment, low vision and blindness vary across the world, ranging from age-related macular degeneration, refractive errors like high myopia, cataract, diabetic retinopathy, glaucoma, retinal detachment, retinitis pigmentosa, retinopathy of prematurity, optic nerve diseases like optic atrophy, hereditary, macular degeneration (Stargardt's disease), albinism, strabismic amblyopia, nystagmus to brain damage of any etiology [19-23].

In this our study the commonest causes of low vision were glaucoma (35.2\%), oculocutaneous albinism (16.7\%), degenerative myopia (7.4\%), maculopathies (7\%), congenital glaucoma $(7 \%)$, retinitis pigmentosa $(6 \%)$, optic atrophy $(6 \%)$ and age-related macular degeneration (4\%) [Figure 1]. In Ekiti State, Nigeria, Ajayi., et al. in a hospital-based study among 445 subjects observed that cataract was the leading cause of low vision [15]. Similar studies in various parts of Nigeria found corroborates the finding that cataract is the leading cause of low vision [24-28]. It has been observed that although cataract is relatively easily, safely and cost efficiently treatable and in spite of the increasing rates of cataract surgery, cataract is still the leading cause of blindness and visual impairment worldwide especially in developing countries [29,30]. Our study was conducted in a specialized low vision clinic in a tertiary eye hospital where cataract surgeries are carried out and blindness/low vision due to cataract may no longer be a contributing factor to low vision unlike community-based studies. Furthermore, our study population was 164 patients attending low vision clinic (with smaller study population). These reasons could account for the difference in observations made in the etiology of low vision in our environment.

In the management of patients with low vision, it is expediate to illicit important elements in the ocular and systemic medical history of the patients such as the possible cause of the low vision, disease progression, associated or predisposing systemic disease and any deficit in the patient that may pose difficulty in using certain devices such as arthritis and tremors. Also, history of glare, the type of occupational and hobbies of the patient are important details that will aid in the effective management of a patient with low vision.

Low vision aids could be optical and non-optical, electronic and non-electronic devices used to assist patients with low vision achieve optimal functional vision. Examples of optical low vision devices are hand held telescopes, mounted telescopes, spectacles, prisms, hand-held magnifiers, standing magnifiers, illuminated and non-illuminated optical devices. Examples of non-optical devices are glare reduction devices, contrast enhancement devices, flexible-arm task lamps, full spectrum light bulbs, absorptive sun lenses/sun glass, colored acetate sheets. Electronic low vision aids could be computer softwares, electronic devices-video magnifier (CCTV), e- readers - iPad and other electronic readers, smartphones and tablets (both apple and android based smartphones and tablets magnify while I-read and I-loupe use camera device and light source to magnify and illuminate texts), sight-book application digitally communicate vision changes and map-quest application provides voice-guided directions [31-33]. Other low vision accessory devices in use are talking watches, clocks, white canes, guiding dogs, writing guides and tactile markers. 
In this study, telescope was the most frequently preferred low vision aid among the study population (38\%). Other devices were spectacle magnifiers (15.7\%), hand-held magnifiers (8\%), standing magnifiers $(7 \%)$, electronic magnifiers $(1 \%)$, photochromic antireflective lenses (1\%) and Contact lens (1\%). Thirty-two percent of the study population were referred for various rehabilitative treatments and procedures [Figure 2]. Majority of the participants of this study (38\% of the study population, consisting of $23.2 \%$ males and $14.8 \%$ females) preferred telescopes to other devices. A total of $32(29.6 \%)$ participants were referred for various rehabilitative measures. This study compares well with the study of AckuakuDogbe., et al. in Ghana, where majority of the participants preferred magnifiers as low vision devices for near and telescopes for distant vision with varying degrees of magnifications [18].

Counselling and referral were offered to School for the Blind for further management and rehabilitation to the severally visionimpaired which could not be ameliorated with available low vision aids.

\section{Conclusion}

Glaucoma, oculocutaneous albinism and degenerative myopia are important etiological factors in low vision in Niger-Delta. Low Vision services should be expanded and improved in order to provide the needed services and devices for optimum functional capacities of clients with low vision.

\section{Financial Support and Sponsorship}

Nil.

\section{Conflicts of Interest}

There are no conflicts of interest.

\section{Bibliography}

1. World Health Organization. "Global initiative for the elimination of avoidable blindness". Geneva, World Health Organization, WHO/PBL/97.61Rev.1 (1997).

2. World Health Organization. VISION 2020: The right to sightThe global initiative for the elimination of avoidable blindness. Magnitude and causes of visual impairment. Fact Sheet No. 282. Geneva: World Health Organization (2004).

3. World Health Organization. Fact Sheet No 282. Visual Impairment and blindness (2014).
4. Thylefors B. "A simplified methodology for the assessment of blindness and its main causes". World Health Statistics 40 (1987): 129-141.

5. Frick KD and Foster A. "The magnitude and cost of global blindness: An increasing problem that can be alleviated". American Journal of Ophthalmology 135 (2003): 471-476.

6. Entekume G., et al. "Prevalence, Causes, and Risk Factors for Functional Low Vision in Nigeria: Results from the National Survey of Blindness and Visual Impairment". Investigative Ophthalmology and Visual Science 52 (2011): 6714-6719.

7. Abdull MM., et al. "Causes of blindness and visual impairment in Nigeria: the Nigeria national blindness and visual impairment survey". Investigative Ophthalmology and Visual Science 50.9 (2009): 4114-4120.

8. World Health Organization. "Strategies for the prevention of blindness in national programmes-a primary health care approach". Geneva: World Health Organization (1997).

9. Attebo K., et al. "Visual acuity and causes of visual loss in Australia: The Blue Mountain eye study". Ophthalmology 103 (1996): 357-364.

10. Klaver CC., et al. "Age-specific prevalence and causes of blindness and visual impairment in an older population: The Rotterdam Study". Archives of Ophthalmology 116 (1998): 653658

11. VanNewkirk M., et al. "Causes-specific Prevalence of bilateral visual impairment in Victoria, Austrialia: The Visual Impairment Project". Ophthalmology 108 (2001): 960-967.

12. Vijaya Lingam., et al. "Prevalence and causes of low vision and blindness in an urban population. The Chennai Glaucoma Study". Indian Journal of Ophthalmology 62.4 (2014): 477-481.

13. Ngondi J., et al. "Prevalence and Causes of Blindness and Low Vision in Southern Sudan". PLoS Medicine 3.12 (2006).

14. Monye HI., et al. "A situational report on low vision services in tertiary hospitals in South-East Nigeria". Nigerian journal of Clinical Practice 23.7 (2000): 919-927.

15. Ajayi I., et al. "Prevalence and Causes of Visual Impairment in Ekiti, Nigeria: A Hospital Based Study". Open Access Journal of Ophthalmology 3.4 (2018): 000158. 
16. World Health Organization. Global Initiative for the Elimination of Avoidable Blindness: Action Plan 2006-2011, World Health Organization, Geneva, Switzerland (2007).

17. World Health Organization, State of the World's Sight: VISION 2020: Right to Sight: 1999-2005, World Health Organization, Geneva, Switzerland.

18. Ackuaku-Dogbe EM., et al. "Causes of Low Vision and their Management at Korle Bu Teaching Hospital, Accra, Ghana". Journal of the West African College of Surgeons 6.3 (2016): 105122.

19. Resnikoff S., et al. "Global data on visual impairment in the year 2002". Bulletin of the World Health Organization 82 (2004): 844-851.

20. World Health Organization. Magnitude and Cause of Visual Impairment. WHO Fact Sheet No. 282. Geneva: WHO (2011).

21. Kyari F., et al. "Prevalence of blindness and visual impairment in Nigeria: The National Blindness and Visual Impairment Study". Investigative Ophthalmology and Visual Science 50 (2009): 2033-2039.

22. Venkata G., et al. "Current estimates of blindness in India”. British Journal of Ophthalmology 89 (2005): 257-260.

23. Onua AA., et al. "The burden of blindness and visual impairment according to age and gender: A case study of Emohua local government area, Nigeria". Port Harcourt Medical Journal 10.2 (2016): 73-78.

24. Sijuwola 00 and Fasina O. "Etiology of visual impairment among ophthalmic patients at Federal Medical Centre, Abeokuta, Nigeria". Journal of the West African College of Surgeons 2.4 (2012): 38-50.

25. Omotoye OJ., et al. "Bilateral Blindness: Prevalence and Their Utilization of Existing Eye Care Facilities in a Nigerian Rural Community". IOSR Journal of Dental and Medical Sciences 9.2 (2013): 54-59.

26. Ajite KO., et al. "Utilization of Eye Care Services Among Staff of a Tertiary Hospital". Asia-Pacic Journal of Ophthalmology 2 (2013): 28-31.

27. Rahmani B., et al. "The cause-specific prevalence of visual impairment in an urban population. The Baltimore Eye Survey". Ophthalmology 103 (1996): 1721-1726.
28. Oluleye TS., et al. "Causes of blindness in Southwestern Nigeria: A general hospital clinic study". European Journal of Ophthalmology 16.4 (2006): 604-607.

29. Pascolini D and Mariotti SP. "Global estimates of visual impairment: 2010". British Journal of Ophthalmology 96.5 (2012): 614- 618.

30. Bourne R., et al. "Causes of vision loss worldwide, 1990-2010: a systematic analysis". Lancet Global Health L (2013): e339e349.

31. https://nelowvision.com/product/davinci-pro/

32. https://esightyewear.com>low-vision

33. https://emedicine.medscape.com>low-vision

\section{Volume 4 Issue 12 December 2021}

C All rights are reserved by Onua AA and Pepple GF. 